\title{
APROXIMACIONES A LOS ESTADOS FINANCIEROS Y A SU INFLUENCIA EN EL DERECHO EMPRESARIAL
}

\author{
APPROACHES TO THE FINANCIAL STATEMENTS AND TO \\ THEIR INFLUENCE ON BUSINESS LAW
}

Edison Paul Tabra Ochoa

\begin{abstract}
Resumen:
El presente artículo pretende relacionar el tema de los estados financieros con el derecho comercial. En tal sentido, este trabajo desarrolla los principales fundamentos contables y financieros de los estados financieros y luego los relaciona con la normatividad societaria, tributaria y penal. El estudio incluye además una serie de aclaraciones para que el lector pueda comprender el rol que la información económica desempeña en el ámbito jurídico.
\end{abstract}

\section{Palabras Claves:}

Estados financieros, derecho empresarial, empresa, administración, gerencia, directorio.

\begin{abstract}
:
The academic article has the main purpose to explain theory and qualities of financial statements and relation to business law. From a legal perspective, the paper works fundaments of financial statements and role in commercial, tax, and criminal law. Besides, it makes a lot of clarifications about its work in order to be clearly understood by readers.
\end{abstract}

\section{Key words:}

Financial statements, business law, enterprise, administration, CEO, board of directors.

\section{Introducción}

El estudio de la empresa se ha convertido en una prioridad en estos últimos años. El derecho mercantil o derecho comercial cada vez más usan el término empresa en vez de "comercio". Así se puede afirmar que hablar de derecho de la empresa simboliza la evolución y la modernización de los comercios y su sustitución por formas de organización más profesionales (Tabra, p. 2016). Pero, asimismo, asumimos la idea que cada vez es frecuente encontrar que las competencias que necesita todo especialista en derecho de la empresa trascienden lo meramente legal. Por ende, el estudio de materias económicas, financieras y de gestión es cada vez más necesario para entender el funcionamiento de la empresa en la actualidad y su funcionamiento cada vez más complejo en la fecha.

Así, por ejemplo, el Anteproyecto de la Ley Marco del Empresariado define a la empresa como la "organización económica dedicada a la producción o comercialización de bienes o a la prestación de servicios" (1998). Esta noción coexiste con aquella que conceptúa a las empresas como el "conjunto de elementos personales, materiales e inmateriales organizados por el empresario para el ejercicio de una actividad económica de producción de bienes o prestación de servicios para el mercado" (Artículo 131-1, Proyecto de Código Mercantil Español, 2013). Estas nociones tienen como denominador común que resaltan la organización para el funcionamiento de la actividad empresarial pero no otorgan una aproximación legal de su concepción. 
En este sentido, Alchiam \& Demsetz proponen que la empresa constituye un punto de equilibrio de los intereses de quienes son parte de la empresa: inversor, empleado, proveedor entre otros. De acuerdo a su postura, cada uno de ellos aporta capital, mano de obra o insumos para la constitución y funcionamiento de la empresa. En este punto, el derecho juega un papel importante porque sirve como herramienta legal que garantizará el funcionamiento de la actividad económica por medio del uso de contratos (Zingales, 1997, 4). Según Rajan y Zingales, de esta forma, el sistema jurídico asegura el proceso de inversión en capital, insumos o mano de obra, entre otros, que cada integrante hace para el funcionamiento eficaz de la empresa (p. 5).

Ahora bien, la naturaleza económica de la empresa y sus actividades en el mercado generan la necesidad de conocer materias que exceden lo estrictamente legal como son la economía, la contabilidad, las finanzas, la gestión y la ética, entre otras. En este caso, la contabilidad se ha convertido en una herramienta necesaria para el ejercicio del gobierno en toda organización empresarial. La contabilidad según Tanaka se asocia a la noción del "lenguaje de los negocios" y se puede definir como el sistema por el cual las empresas miden, registran, sumarizan y presentan el resultado económico y financiero de sus actividades (Tanaka, 2015, p. 17). En este proceso de entendimiento económico de la actividad empresarial, los estados financieros desempeñan un rol importante para su supervivencia en el mercado porque grafica la situación de la empresa a nivel financiero, labor y mejoras hechas con el fin de optimizar su gobierno (Tanaka, 2015, p. 103). Pese a su importancia, no existen muchos trabajos que desarrollen su influencia en el ámbito jurídico empresarial. Por ello, cabe hacernos la siguiente pregunta ¿Cuál es la importancia de los estados financieros? Y ¿cuál es su utilidad en el derecho de la empresa?

Estas dos preguntas serán resueltas en el siguiente trabajo de investigación que tiene como objetivo determinar la relación que tienen los estados financieros con el derecho empresarial. Para una mejor comprensión del tema por parte del lector, el presente trabajo se ha estructurado en 4 partes: la primera desarrolla los fundamentos teóricos de los estados financieros y se precisa sus elementos y principales características conceptuales. A su vez, el segundo punto desarrolla su ubicación y desarrollo en las Normas Internacionales de Contabilidad (NIC), en especial con la NIC no 1, que desarrolla los criterios que deben reunir los estados financieros desde una perspectiva contable. A su turno, la tercera parte ubica el concepto de los estados financieros en el campo del derecho empresarial, destacando su influencia, especialmente, en la normatividad societaria, tributaria y penal económica.

\section{Aspectos teóricos de los estados financieros}

\subsection{Definición}

La doctrina especializada desarrolla la noción de estados financieros desde tres perspectivas conceptuales. La primera de ellas los considera como el conjunto de informes contables que realizan la labor de resumir la situación económica y financiera de la empresa con el objetivo de facilitar o posibilitar la toma de decisiones por parte de la gerencia (Rivero, 2014, p. 17 y Flint 2006, p. 460). También, como ya se indicó anteriormente, Tanaka los considera como el "producto final y principal de procesamiento de las transacciones de una empresa" (2015, p. 103). Por último, la otra noción conceptual los entiende como la creación de la "situación financiera" y los "resultados" de una empresa de acuerdo a los parámetros de "coherencia" y del "conocimiento del negocio" (Chong, 1992, pp. 85-86).

De estas tres concepciones, consideramos que los estados financieros son los mecanismos necesarios para facilitar la toma de decisiones de la gerencia general o mejor aún, de la administración en general de la empresa. A nuestro entender este criterio tiene una relación más entendible con el derecho aplicado al gobierno de la empresa. 


\subsection{Características}

Se pueden destacar las siguientes características de los estados financieros:

\section{a. Deben seguir ciertas pautas contables que permiten dar certeza a la gerencia}

Los estados financieros otorgan la información económica a la administración a fin de adoptar los cambios que se requieren para mejorar la actividad empresarial y hacerla sostenible a largo plazo.

\section{b. Aplican los principios básicos de la contabilidad}

Para Tanaka ${ }^{1}$, los estados financieros hacen uso de seis principios básicos: devengado, negocio en marcha, entidad económica, unidad monetaria estable, mercado de libre competencia y periodicidad (Tanaka, 2015, p. 105). Flint opina que deberían usarse los principios de contabilidad generalmente aceptados (PCGA) y son los criterios de entidad, empresa en marcha, periodo contable, bienes económicos, equidad, valuación del costo, exposición. Moneda común denominador, uniformidad, materialidad, prudencia, objetividad, realización y devengado (2006, pp. 459-460).

\section{c. Poseen características cualitativas}

Los estados financieros deben cumplir con brindar valiosa información sobre la situación económica de la empresa siguiendo las reglas cualitativas de la comprensibilidad, relevancia, confiabilidad, comparabilidad, consistencia, equilibrio entre costo y beneficio, y significatividad o materialidad.

\section{d. Está compuesto por cuentas contables}

Según Flint, los estados financieros comprenden el uso de cuatro cuentas (2006, pp. 461484): el balance general (situación de activos y pasivos en una empresa y el estado de su patrimonio), el estado de resultados o estado de ganancias y pérdidas (permite hallar cual es la utilidad o pérdida de una empresa en un período), el estado de cambios en el patrimonio neto (muestra los cambios en el patrimonio neto) y el estado de flujo de efectivo (mide la viabilidad de la empresa). Según Rivero las cuentas contables se interrelacionan entre sí y entre diversos resultados obtenidos en los mismos (2014, p. 33).

\subsection{Elementos de los estados financieros}

Existen elementos para cada uno de los estados financieros (Rivero, 2014, pp. 18-32):

a. El balance general que se compone de activos (recursos que controla la entidad y que se espera obtener beneficios económicos para la entidad) y pasivos (obligaciones o deudas presentes de la entidad como resultado de hechos pasados).

b. El estado de resultados que comprende: ingresos (aumento de activos o disminución de pasivos de una entidad), costos (disminución de activos o aumento de pasivos, gastos (costo de los bienes o servicios adquiridos por la compañía, los cuales han generado ingreso) y pérdida (costo de los bienes o servicios que, habiéndose consumido, no han logrado generar ingresos).

c. El estado de flujos de efectivo y cambios en el patrimonio usan indistintamente los elementos del balance general y del estado de pérdidas y ganancias. 


\section{Los Estados Financieros según las Normas Internacionales de Contabilidad(NIC) ${ }^{2}$}

Las NIC son estándares o recomendaciones de la International Accounting Standards Board que indican como los representantes de una empresa deben de preparar y presentar los estados financieros. Aquí podemos destacar las siguientes normas:

\subsection{Norma Internacional de Contabilidad 1 (NIC $n^{\circ}$ 1). Presentación de estados financieros}

\subsubsection{Ubicación}

Los estados financieros se encuentran desarrollados en la norma internacional de contabilidad $n^{\circ} 1$. En esta norma se precisan aspectos como la base de presentación, los requerimientos generales, las guías para determinar su estructura y los requisitos mínimos sobre su contenido.

\subsubsection{Definición}

El concepto de "estados financieros" es diferente a aquella desarrollada en las Normas internacionales de información financiera (NIIF). Representa la situación estructurada de la "situación" y "rendimiento" financiero de una entidad (NIC 1, 2018, p. 3).

\subsubsection{Objetivo}

Los estados financieros tienen como objetivo suministrar información sobre tres aspectos importantes de una entidad que permita adoptar decisiones en la gestión de una empresa (NIC 1 2018: 3). Nos referimos a su situación financiera, rendimiento financiero y a sus flujos de efectivo. Para el cumplimiento de su función, los estados deben de presentar información sobre los componentes económicos de una entidad: (a) activos; (b) pasivos; (c) patrimonio; (d) ingresos y gastos, en los que se incluyen las ganancias y pérdidas; (e) aportaciones de los propietarios y distribuciones a los mismos en su condición de tales; y (f) flujos de efectivo $(2018$, p. 3).

\subsubsection{Cuentas contables que componen los estados financieros}

De acuerdo a esta norma, los estados financieros deben entregar información contable sobre diversos aspectos económicos de la entidad. Estos son:

\section{a. Estado de situación financiera al final del día}

También se le conoce como "balance general". Su función es de presentar la "posición financiera" de la empresa desde que se constituyó hasta la fecha en que se elabora el presente balance (Tanaka, 2015, p. 110).

\section{b. Estado de resultado integral del periodo}

Según Tanaka, en este estado se refleja la "situación económica" de la empresa así como los ingresos y egresos que realizó a la fecha (2015, p. 111).

\section{c. Estado de cambios en el patrimonio del periodo}

Este estado refleja los cambios que se han producido en el patrimonio de una empresa.

\section{d. Estado de flujos de efectivo del periodo}

El estado de flujos de efectivos muestra las variaciones de dinero en una empresa.

2 Información tomada del portal del Ministerio de Economía y Finanzas (MEF). Disponible en: http://www.mef.gob.pe/index. php?option=com_content\&view=article\&id=3348\&ltemid=101379\&lang=es (última consulta: 26 de noviembre de 2015). 
e. Notas (resumen de políticas contables más significativas y otra información explicativa).

Las notas muestran la información adicional sobre los estados contables.

f. Un estado de situación financiera al principio del primer periodo comparativo. En caso de que la empresa aplique una política contable retroactivamente o realice una reexpresión retroactiva de partidas en sus estados financieros, o cuando reclasifique partidas en sus estados financieros (NIC 1, 2018, p. 4).

\subsubsection{Características generales}

Según la NIC 1, los estados financieros se deben elaborar y presentar siguiendo estas características (NIC 1, 2018, pp. 6-9).

\section{a. Criterio de Razonabilidad}

Toda entidad debe presentar la situación financiera y el rendimiento económico financiero y los flujos de efectivo de una entidad según el criterio "razonable". Para cumplir este criterio la entidad debe cumplir con tres pautas principales:

Selección y aplicación de las políticas contables según la NIC 8.

- Uso de información según los criterios de relevancia, fiabilidad, comparabilidad y comprensibilidad.

Utilización de información adicional si los requerimientos exigidos por las NIIF resulten insuficientes para la comprensión de determinadas transacciones, otros sucesos 0 condiciones sobre la situación financiera y el rendimiento financiero de la entidad.

\section{b. Criterio del "negocio en marcha"}

La elaboración de los estados financieros se hace con la creencia que la empresa seguirá "en funcionamiento" salvo que gerencia indique que sus intenciones son liquidar la entidad o cesar en su actividad o no exista otra alternativa más realista que proceder de una de estas formas. En casos de incertidumbres que perjudiquen el funcionamiento de la empresa, la gerencia deberá revelarlas en los estados financieros. Similar deber deberá hacerse en caso se omita el uso de este criterio.

\section{c. Criterio del "devengo"}

La elaboración de los estados financieros se hará según la base contable de acumulación (devengo).

\section{d. Criterio de la "materialidad" y "agrupación de datos"}

Los estados financieros presentarán por separado sus partidas de naturaleza o función distinta, a menos que no tengan importancia relativa.

\section{e. Compensación}

La compensación se hará uso a menos que sea necesario o requiera una NIIF, caso contrario no se utilizará.

\section{f. Frecuencia de la información}

La entidad debe presentar un juego completo de estados financieros (información comparativa) al menos anualmente. 


\section{g. Información comparativa}

Una entidad revelará información comparativa respecto del periodo anterior para todos los importes incluidos en los estados financieros del periodo corriente. La excepción es si las NIIF permitan o requieran otra cosa.

h. Criterio de la "uniformidad en la presentación"

La presentación y clasificación de las partidas en los estados financieros se mantendrán. La excepción recae en los casos de cambio de naturaleza de las actividades de la entidad o una revisión de sus estados financieros o una NIIF requiera un cambio en la presentación.

\section{Los Estados Financieros según las Normas Internacionales de Información Financiera (NIIF) ${ }^{3}$}

Al igual que las NIC, las NIIF son estándares internacionales de contabilidad que regulan la forma cómo debe presentarse la información económica que emite una empresa. Dentro de las principales que poseen relación con los estados financieros podemos destacar:

\subsection{Normas Internacionales de Información Financiera $\mathbf{N}^{\circ} 1$ (NIIF 1). Adopción por primera vez de las normas internacionales de información financiera}

Esta NIIF 1 tiene como objetivo asegurar que los primeros estados financieros se elaboren conforme a las NIIF de una entidad, así como sus informes financieros intermedios, relativos a una parte del periodo cubierto por tales estados financieros.

\subsection{Normas Internacionales de Información Financiera $\mathrm{N}^{\circ} 9$ (NIIF 9). Instrumentos financieros}

Esta norma establece los principios que debe reunir la información financiera sobre activos financieros y pasivos financieros, de forma que la información sea útil y relevante para los usuarios de los estados financieros para la evaluación de los importes, calendario e incertidumbre de los flujos de efectivo futuro de la entidad.

\subsection{Normas Internacionales de Información Financiera No 15 (NIIF 15). Ingresos de actividades ordinarias procedentes de contratos con clientes}

Esta norma establece los principios que aplicará una entidad para presentar información útil a los usuarios de los estados financieros sobre la naturaleza, importe, calendario e incertidumbre de los ingresos de actividades ordinarias y flujos de efectivo que surge de un contrato con un cliente.

\section{Los Estados Financieros y su relación con el Derecho Empresarial}

\subsection{Los estados financieros y su relación jurídica con la empresa}

Desde una perspectiva legal, concretamente, la Ley General de Sociedades establece en su artículo $190^{\circ}$, inciso 3, que el gerente general es responsable de la veracidad de los sistemas de contabilidad de una sociedad comercial y que en caso no hacerlo puede ser sujeto de una pretensión de responsabilidad social o individual. Como consecuencia de esta pretensión, el gerente puede ser objeto de remoción automática de su cargo y ser imposibilitado para ejercer cualquier otra función en la empresa, conforme al artículo $195^{\circ}$. Ello sin contar con la responsabilidad penal y civil que su conducta acarree.

Tomado del portal del Ministerio de Economía y Finanzas (MEF). Disponible en: http://www.mef.gob.pe/index. php?option=com_content\&view=article\&id=3347\&ltemid=101380\&lang=es (consulta 26 de noviembre de 2015). 
También, los artículos $50^{\circ}$, incisos d ye, y $52^{\circ}$ de la Ley de la Empresa Individual de Responsabilidad Limitada (EIRL) establece que las funciones del gerente consisten en el deber de cuidado de la contabilidad y la formulación de las cuentas y el balance; de informar periódicamente al titular sobre la actividad de la EIRL; y de garantizar la existencia y veracidad de los libros, documentos y cuentas que ordenen llevar las normas legales vigentes. De igual forma, creemos que es en el caso de las empresas persona natural. En ellas el comerciante asume dicha responsabilidad en su condición de titular encargado de la organización o administración de una unidad económica creada para la comercialización de bienes o prestación de servicios conforme al artículo $4^{\circ}$ del TUO de la Ley de Impulso al Desarrollo productivo y al Crecimiento Empresarial (2013) ${ }^{4}$.

Sin embargo, creemos que, al margen de esta exigencia jurídica a los administradores, los estados financieros juegan un papel importante porque permiten la adopción de decisiones de quienes administran una empresa: el titular, la junta general de accionistas, el directorio o el gerente. En el caso de las sociedades comerciales es muy importante porque facilita el ejercicio de los derechos de los accionistas como son la participación, el voto y la impugnación de acuerdos societarios. De acuerdo a la situación financiera, los accionistas pueden adoptar diversas decisiones trascendentales en favor de la empresa como son optar por aprobar los procesos de fusión con otra empresa u optar por otra operación de reorganización societaria ${ }^{5}$. Asimismo, en caso de desacuerdo con la mayoría de accionistas el accionista o socio puede impugnar un acuerdo que se haya adoptado en junta tomando como referencia los estados financieros de la empresa ${ }^{6}$. Incluso el juez, ante quien se impugna esa decisión, debe de entender a los estados financieros como el mecanismo que muestra el estado económico de la empresa a fin que otorgar una medida cautelar y elaborar la sentencia judicial ${ }^{7}$.

Asimismo, de acuerdo al artículo $152^{\circ}$ de la Ley General de Sociedades para el directorio se aplicaría las mismas responsabilidades que en el caso del gerente general que ya se ha discutido anteriormente y en todo lo que corresponda su función ${ }^{8}$.

\subsection{La funcionalidad jurídica de los estados financieros}

Dentro del ámbito del derecho de la empresa podemos mencionar que la aplicación de los estados financieros se da en diversas áreas legales como el derecho comercial, el derecho tributario y el derecho penal. También su aplicación tiene consecuencias en el derecho civil y derecho procesal.

\section{a. Elaboración de la memoria e información financiera}

En el derecho comercial o mercantil, los estados financieros se encuentran regulados en los artículos $221^{\circ}$ y $223^{\circ}$ de la Ley General de Sociedades. En este acápite se parte como una obligación de los directores de la sociedad comercial de presentar a los accionistas los estados financieros y la memoria. El artículo $221^{\circ}$ promueve que el directorio tiene la obligación de formular la memoria, los estados financieros y la propuesta de distribución de utilidades. Para el caso de los estados financieros la norma establece que debe presentarse de forma "clara" y "precisa" la situación económica y financiera de la sociedad, el estado de sus negocios y los resultados obtenidos en el ejercicio vencido.

4 La norma como tal define la noción de "micro y pequeña empresa". Sin embargo, creemos dicha clasificación se complementa con el artículo $5^{\circ}$ que prescribe que las microempresas son aquellas unidades económicas que poseen ventas hasta 150 UIT mientras que la pequeña empresa posee ventas al año de 150 UIT a 1700.

5 Conforme lo establecen las atribuciones de la junta general de accionistas descritas en los artículos $147^{\circ}-148^{\circ}$ de la Ley General de Sociedades.

6 Artículo $139^{\circ}$ de la Ley General de Sociedades.

7 Conforme lo establecen las atribuciones de la junta general de accionistas descritas en los artículos $114^{\circ}-115^{\circ}$ de la Ley General de Sociedades.

8 Artículo 152.- Administradores

La administración de la sociedad está a cargo del directorio y de uno o más gerentes, salvo por lo dispuesto en el artículo 247. 
En este punto podemos deducir que la norma comercial obliga a los directores que presenten el balance general y el estado de resultados o estados de ganancias y pérdidas. Esto con el objetivo que los accionistas puedan revisarlos antes de la celebración de la junta obligatoria anual. De forma complementaria, el artículo 223 establece que los estados financieros se deben elaborar de acuerdo con las normas de contabilidad vigentes en el país.

Entonces podemos ir concluyendo que la Ley General de Sociedades establece dos funciones importantes que desempeñan los estados financieros. La primera de garantizar el derecho a la información de los accionistas a fin que puedan ejercer correctamente y de forma conexa su voto en la junta general anual de la sociedad. También, podemos destacar la importancia de los estados financieros en la toma de decisiones de gestión de la empresa. Este criterio se utiliza de forma analógica, según sea el caso y la naturaleza, en los otros tipos de empresa.

\section{b. Responsabilidad de los administradores de una empresa}

La ley impone a los directores y gerentes de una empresa la responsabilidad de la elaboración de los estados financieros de forma diferenciada. Así, mientras los directores tienen responsabilidad por no elaborar los estados financieros una vez finalizado el ejercicio comercial de la empresa, los gerentes tienen responsabilidad por la existencia, regularidad y veracidad de los sistemas de contabilidad ${ }^{9}$. Esto permite deducir que la responsabilidad de velar por la elaboración de los estados financieros del directorio es ocasional mientras que la del gerente es permanente. Esto no sucederá en aquellos tipos de empresa donde el rol de directivo y gerente lo asuma una misma persona (SAC por ejemplo).

\section{c. Reparto de utilidades}

La Ley general de sociedades establece que el reparto de utilidades solo se realiza según los estados financieros al cierre de un periodo determinado o la fecha de corte en circunstancias especiales que acuerde el Directorio ${ }^{10}$. Sin embargo, si los socios, o los directivos, de una empresa falsean los estados financieros y se reparten utilidades inexistentes la norma establece responsabilidad solidaria (devolución del dinero).

\section{d. Derechos de los accionistas}

La ley general de sociedades permite a los accionistas o socios solicitar información sobre la situación económica, financiera y legal de la empresa según los criterios de "suficiencia", "fidedigna" y "oportunas"11. En este caso, el Directorio, o quien haga sus veces, tiene el deber de otorgar la información al socio bajo sanción de responsabilidad penal y civil. En este acápite la utilidad de conocer los estados financieros corresponderá al accionista ya que podrá interpretar el estado económico de la empresa y le permitirá ejercitar sus demás derechos como el ejercicio del voto y de la impugnación de acuerdos societarios ${ }^{12}$. Asimismo, ambas normas descritas destacan que un tercero (público) puede solicitar la información económica a la empresa, revisarla y, de considerar necesario, impugnar aquellos actos que considere incorrectos en la gestión de la gerencia o del directorio ${ }^{13}$.

\subsection{Derecho Tributario}

En el derecho tributario la noción y el conocimiento práctico de los estados financieros son esenciales para la administración de una empresa. Su conocimiento permite prevenir que la empresa cometa conductas que generen en una sanción administrativa por parte de la Administración Tributaria.

Artículos $221^{\circ}$ y $190^{\circ}$ de la Ley General de Sociedades respectivamente.

Artículo $40^{\circ}$ de la Ley General de Sociedades.

Artículo $175^{\circ}$ de la Ley General de Sociedades.

Artículo $139^{\circ}$ de la Ley General de Sociedades.

Artículo $150^{\circ}$ y $175^{\circ}$ de la Ley General de Sociedades. 
El artículo $177^{\circ}$ en sus incisos 8 y 9 del Código Tributario establece que el incumplimiento de dos conductas relacionadas al manejo de estados financieros constituye una infracción y posterior sanción:

a. Autorizar estados financieros, declaraciones, documentos u otras informaciones exhibidas o presentadas a la Administración Tributaria conteniendo información no conforme a la realidad, o autorizar balances anuales sin haber cerrado los libros de contabilidad

El incumplimiento de esta conducta, tipificada en el inciso 8, genera una sanción de $50 \%$ de la UIT para el caso de empresas generadoras de tercera categoría. Para las empresas del Régimen Especial del Impuesto a la Renta la multa será del $25 \%$ de la UIT. Para el caso de las Empresas Individuales de Responsabilidad Limitada que están en el Nuevo Régimen Único Simplificado (Nuevo RUS) la multa será $20 \%$ de la UIT.

b. Presentar los estados financieros o declaraciones sin haber cerrado los libros contables El incumplimiento de esta conducta, tipificada en el inciso 9, genera una sanción de $0.3 \%$ de los ingresos netos para el caso de empresas generadoras de tercera categoría. Igual monto se aplicará para las empresas del Régimen Especial del Impuesto a la Renta. Para el caso de las Empresas Individuales de Responsabilidad Limitada que están en el Nuevo Régimen Único Simplificado (Nuevo RUS) la multa será $20 \%$ del total de Ingresos o al cierre de actividades.

\subsection{Derecho penal}

En el derecho resulta útil el conocimiento de los estados financieros porque permiten determinar si existió responsabilidad penal de parte de los administradores o de quienes prestaron su colaboración para que cometa el delito. El código penal peruano destaca las siguientes figuras que se sancionan:

\section{a. Delito de Administración Fraudulenta (artículo 198 del Código Penal)}

Este delito castiga aquellas conductas que cometan los directivos de una empresa. El fundamento radica en la necesidad de castigar "la expectativa normativa de conducta de que los directivos o administradores de una persona jurídica no abusarán o incumplirán sus facultades de administración, perjudicando patrimonialmente a ésta o a terceros" (García Cavero, 2007, p. 363).

El artículo 198 del Código Penal indica que "será reprimido con pena privativa de libertad no menor de uno ni mayor de cuatro años el que ejerciendo funciones de administración o representación de una persona jurídica, realiza, en perjuicio de ella o de terceros, cualquiera de los actos siguientes: 1) Ocultar a los accionistas, socios, asociados, auditor interno, auditor externo, según sea el caso o a terceros interesados, la verdadera situación de la persona jurídica, falseando los balances, reflejando $u$ omitiendo en los mismos beneficios o pérdidas o usando cualquier artificio que suponga aumento o disminución de las partidas contables".

\section{b. Delito de infracción de deberes contables tributarios}

Este delito penal castiga los incumplimientos de ciertos deberes contables indispensables para la labor de control de la administración tributaria, en la medida que con ello se aligera el camino para una posterior defraudación tributaria (García Cavero 2007: 676). Este tipo de delito no necesita que se perjudique la recaudación tributaria ya que solo necesita que se acredite el incumplimiento de los deberes contables tributarios. En este caso se puede suscitar la conducta del contador que incumpla con la obligación de llevar contabilidad, con el deber de anotación, con el deber de veracidad y con el deber de conservación (García Cavero, 2007, pp. 680-683).

El artículo $5^{\circ}$ del Decreto Legislativo $n^{\circ} 813$, Ley Penal Tributaria, establece que aquella persona responsable de llevar libros y registros contables será sancionada con pena privativa de la libertad 
no menor de 2 (dos) ni mayor de 5 (cinco) años y con 180 (ciento ochenta) a 365 (trescientos sesenta y cinco) días-multa en caso incurra en las siguientes conductas: incumplimiento de llevar los libros y registros contables; hacer las anotaciones de actos, operaciones, ingresos en los libros y registros contables; realizar anotaciones de cuentas, asientos, cantidades, nombres y datos falsos en los libros y registros contables; y destruir u ocultar total o parcialmente los libros y/o registros contables o los documentos relacionados con la tributación.

\section{CONCLUSIONES}

Sin duda, los estados financieros se han convertido en un instrumento financiero necesario para conocer el estado económico de las empresas. A lo largo de este trabajo hemos encontrado que su función es vital porque permite el ejercicio de los derechos de los accionistas de una sociedad comercial o del titular de una empresa, según sea el tipo, y facilita la administración de las entidades empresariales.

En este sentido, la legislación comercial ha dejado a la normativa contable y financiera la forma como deben elaborarse los estados financieros de cada empresa. Sin duda, las normas internacionales de contabilidad (NIC) y las normas internacionales de información financiera (NIIF) aportan los criterios para la correcta preparación y sistematización de la información de la empresa. Por ello resulta importante que es imprescindible que quien desee explorar el derecho de la empresa, en especial el gobierno de ella, debe contar con nociones básicas de contabilidad. Esto le permitirá identificar las necesidades de la empresa y, por tanto, plantear alternativas de solución que mejoren su funcionamiento y, también, garantice una eficaz participación de los socios.

Por último, creemos importante señalar la necesidad de revisar la legislación dedicada al funcionamiento de la Empresa Individual de Responsabilidad Limitada (EIRL). En relación a los estados financieros, notamos que sus normas no dedican ninguna regla clara al respecto. Asimismo, las empresas persona natural se regulan por el Código de Comercio o normas de promoción a la actividad de micro y pequeña empresa, pero carecen de normas propias y actualizadas. Por ello, el legislador debería prestar atención a este universo y plantear alternativas para facilitar un funcionamiento adecuado de ellas.

\section{REFERENCIAS BIBLIOGRÁFICAS}

- $\quad$ CHONG, Esteban. Contabilidad intermedia. Estados financieros y cuentas del activo. (1992). Lima: Universidad del Pacífico, pp. 46-105.

- $\quad$ BEAUMONT CALLIRGOS, Ricardo. Comentarios a la Ley General de Sociedades. (2004). Cuarta edición. Lima: Gaceta Jurídica, pp. 552-572.

- GARCÍA CAVERO, Percy. La Administración fraudulenta en Derecho penal económico. Parte especial. (2007). Lima: Editorial Grijley, pp. 357-415.

- ELÍAS, Enrique. Derecho societario peruano. La ley general de sociedades del Perú. (2001). Trujillo: Normas legales, pp. 465-517.

- $\quad$ FLINT, Pinkas. Gerencia integral. (2006). Lima: Editora Grijley, pp. 457-513.

- JURISTA EDITORES. Legislación comercial. (2013). Lima: Jurista editores.

- HUNDSKOPF, Oswaldo. Estados financieros fraudulentos de las sociedades anónimas en Derecho de sociedades y gobierno corporativo. (2008). Lima: Editorial Grijley, pp. 87-123.

- MINISTERIO DE ECONOMÍA Y FINANZAS. Normas internacionales de contabilidad oficializadas. Norma internacional de contabilidad 1: Presentación de estados financieros. Consulta 15 de noviembre de 2015.

- http://www.mef.gob.pe/contenidos/conta_publ/con_nor_co/no_oficializ/ES_GVT_ IAS01_2015.pdf

- Ministerio de Justicia y Derechos Humanos. Sistema Peruano de Información Jurídica (SPIJ). (2015). Código Tributario. Fecha de consulta: 22 de noviembre de 2015. 
- RIVERO, Gustavo. Contabilidad I. Tercera edición. (2014). Lima: Universidad del Pacífico.

- SORIANO, María Jesús. Introducción a la Contabilidad y las Finanzas. (2011). Barcelona: PROFIT Editorial.

- $\quad$ SUPERINTENDENCIA NACIONAL DE ADMINISTRACIÓN Tributaria (SUNAT)

- $\quad$ SUNAT: Acogimiento y pago-Nuevo RUS. Consulta: 22 de noviembre de 2015.

- $\quad$ SUNAT: Sala de prensa.

- TABRA OCHOA, Edison. El rol del proxy advisor en el gobierno de la empresa: breve análisis de la realidad peruana. (2016). Tesis de Maestría en Derecho de la Empresa. Lima: Pontificia Universidad Católica del Perú (PUCP).

- TANAKA NAKASONE, Gustavo. Contabilidad y análisis financieros. Un enfoque para el Perú. (2015). Lima: Fondo editorial de la Pontificia Universidad Católica del Perú (PUCP).

- Zingales, Luigi. Corporate governance. National Bureau of Economic Research. (1997). Working paper 6309, pp. 1-19.

\section{Normas}

- $\quad$ Ley General de Sociedades (Ley $n^{\circ} 26887$ ).

- Ley de la Empresa Individual de Responsabilidad Limitada (Decreto Ley 21621).

- TUO Ley de Impulso al Desarrollo Productivo y al Crecimiento Empresarial.

- $\quad$ Anteproyecto de la Ley Marco del Empresariado.

Fecha de recepción: 14 de setiembre de 2018

Fecha de aceptación: 30 de octubre de 2018 